\title{
La Acción Católica en la organización y puesta en marcha del Segundo Congreso Nacional Mariano de Colombia (1939-1946)*
}

\begin{abstract}
Resumen
Este artículo describe y explica las actividades de la Acción Católica para organizar e implementar el segundo congreso mariano. La presente investigación se enmarca en el estudio de la iglesia católica colombiana, enfocada desde la sociología de la religión, la historia del hecho religioso y la historia político religiosa. La metodología que se escogió es de carácter hermenéutico y descriptivo. Este trabajo permite concluir que el Integrismo católico en Colombia intentó cubrir todos los espacios de la vida cotidiana de los católicos, irrumpiendo en ellos a través de María; esto por medio de la celebración de congresos marianos, con los que irrumpió en el inconsciente colectivo de la sociedad para mantener el orden social establecido (ante el liberalismo, protestantismo y comunismo) y enfrentar una nueva etapa en la confrontación política mundial (La Guerra Fría).
\end{abstract}

Palabras claves: Colombia, catolicismo, Virgen María, control social, congresos marianos, historia.

Referencia para citar este artículo: CÁCERES MATEUS, Sergio Armando (2017). "La Acción Católica en la organización y puesta en marcha del Segundo Congreso Nacional Mariano de Colombia (19391946)". En Anuario de Historia Regional y de las Fronteras. 22 (2). pp. 217-245.

Fecha de recepción: 09/07/2016

Fecha de aceptación: 03/03/2017

Sergio Armando Cáceres Mateus: Historiador de la Universidad Industrial de Santander, Colombia. Investigador de Sagrado y Profano, Grupo de Estudios del Hecho Religioso (Colciencias-Universidad Industrial de Santander-Instituto Colombiano para el Estudio de las Religiones en Colombia), Colombia. Miembro del Instituto Colombiano para el Estudio de las Religiones en Colombia (ICER), Colombia. Miembro Adherente de la Asociación Historia Abierta (AHISAB), Colombia. Correo electrónico: scaceres8616@yahoo.com. Código ORCID: 0000-0003-1943-6675.

\footnotetext{
* Este artículo nace desde el 2011 con el proyecto de tesis de pregrado de la Universidad Industrial de Santander, titulado La Acción Católica Colombiana y la resistencia al proyecto liberal de laicización, 1934-1942, con el cual obtuve el título profesional como Historiador. Hacia finales del 2015 retomé esta iniciativa revisando nueva bibliografía y fuentes primarias, que fueron claves para observar un horizonte más amplio y claro, pero que deja muchas preguntar abiertas que tendrán que profundizarse en un próximo artículo.
} 


\title{
Catholic Action in the Organization and Implementation of the Second National Marian Congress of Colombia (1939-1946)
}

\begin{abstract}
This article describes and explains the activities of the Catholic Action to organize and implement the second Marian congress in Colombia. This research is part of the study of the colombian catholic church, approached from the sociology of religion, history of religion and religious political history. The methodology chosen is hermeneutic and descriptive. This work allows us to conclude that the catholic fundamentalism in Colombia attempt to cover all areas of daily life of catholics, breaking into them through the virgin Mary, and holding Marian congresses, with whom broke into the unconscious collective society to maintain social order (against liberalism, communism and Protestantism) and deal a new stage in the global political confrontation (The Cold War).
\end{abstract}

Keywords: Colombia, Catholicism, Virgin Mary, Social Control, Marian Congress, History.

\section{Ação Católica na organização e implementação do Segundo Congresso Nacional Mariano da Colômbia (1939-1946)}

\section{Resumo}

Este artigo descreve e explica as atividades da Ação Católica para organizar e implementar o segundo Congresso Mariano. Esta pesquisa faz parte do estudo da Igreja Católica colombiana e se enfoca a partir da sociologia da religião, história da religião e história política religiosa. A metodologia escolhida é de caráter hermenêutico e descritivo. Este trabalho permite concluir que o fundamentalismo católico na Colômbia tentou abranger todas as áreas da vida diária dos católicos através da Virgem Maria e da celebração de congressos marianos, com os quais entrou no inconsciente coletivo da sociedade para manter a ordem social estabelecida (ante o liberalismo, o protestantismo e o comunismo) e enfrentar uma nova etapa no confronto político global (A Guerra Fria).

Palavras-chave: Colômbia, catolicismo, virgem Maria, controle social, congressos marianos, história. 


\section{Introducción}

Esta investigación se encuentra dividida en dos partes de la siguiente manera: 1. Antecedentes, en donde se realiza un breve recuento sobre la historia de Europa de la doctrina y posterior dogma de la Inmaculada Concepción desde el Siglo XIII hasta el siglo XIX. Igualmente, se explica la creencia y difusión de la virgen María durante el siglo XIX y principios del siglo XX por parte de la iglesia católica, enfocándonos en Colombia. Para finalizar, se describe el contexto político social (Hegemonía conservadora) y la puesta en marcha del primer congreso mariano en Colombia (1919). 2. La Acción Católica Colombiana (A. C.C.) y la organización del segundo congreso mariano de Colombia. En este apartado se explica la creación de la A. C. C. (1933) y la inserción del laico en diversas actividades de la iglesia, sobre todo en lo referente al culto mariano. Asimismo, se describe el proceso que llevó a cabo las directrices nacionales de la A. C. a través de las diócesis para lograr la organización y puesta en marcha del congreso en diferentes parroquias del país (1939-1942). Además se resalta el rechazo del Vaticano a celebrar este en 1942, posponiéndolo hasta 1946, cuestión que generó al interior del catolicismo confusión.

La presente investigación se enmarca en el estudio de la iglesia católica colombiana desde la sociología de la religión, la historia del hecho religioso y la historia político religiosa. La metodología que se escogió es de carácter hermenéutico y descriptivo.

\section{Antecedentes}

En este apartado se realizará el recuento de algunos antecedentes sobre la creencia y lanzamiento positivo de la virgen maría en Europa durante los siglos XIII al XIX. Asimismo, se observa como a través de la Romanización, se implementó a través de las órdenes religiosas un proyecto para una mayor difusión de este icono religioso en Colombia. Por último, se lleva a cabo la descripción de la puesta en marcha del primer congreso nacional mariano, 1919.

\section{La Inmaculada Concepción, patrona y protectora del catolicismo Europeo, Siglos XIII-XIX}

Durante los siglos XIII y XIV el tema central en las facultades de Teología de las mejores universidades del mundo (Oxford y La Sorbona, entre otras), era el de la Inmaculada Concepción de María. Existía una rivalidad entre opositores y partidarios de este dogma que dio sus primeros pasos con Tomas de Aquino y La Suma de Teología ${ }^{1}$. Asimismo, el Beato Juan Duns Escoto (1266-1308), quien estudio en Oxford fue uno de los máximos exponentes de la posición inmaculista liderada por los escolásticos, quienes brindaron las bases teológicas para la posterior creación del dogma. Esta tensión aumentaría con la proclamación del concilio de Basilea (1431-

\footnotetext{
${ }^{1}$ De Aquino, Tomas. Suma de Teología V. Parte III e Índices. Cuestiones 27-30 (Madrid: Biblioteca de Autores Cristianos, 1994), pp. 265-281.
} 
1445) en donde Jean de Rouvroy, procurador de la catedral de Bourges, en la sesión del 18 de diciembre de 1439 declaró como "[...] piadosa doctrina en conformidad con el culto de la iglesia, la fe católica, la recta razón y las Sagradas Escrituras"². Así, la doctrina de la Inmaculada Concepción quedaba aprobada, debía ser mantenida y profesada por todos los católicos, prohibiéndose la enseñanza o prédica contraria a ella y se instituía su fiesta el 8 de diciembre. Sin embargo, al no ser considerado ese concilio como ecuménico esa disposición no quedaba establecida como canónicamente obligatoria. El Papa Sixto IV en su constitución Cum prae excelsa (1477), aprobó la misa y el oficio de la Concepción de María, afirmando al mismo tiempo la libertad en ese tema doctrinal ${ }^{3}$. Posteriormente, en el Concilio de Trento (1545-1563) señaló la excepción de la Virgen María al castigo universal del pecado original. Asimismo, dio las bases para los postulados de Contrarreforma y de persecución a la herejía. Casi un siglo después, el Papa Alejandro VII, en su Sollicitudo omnium Ecclesiarum (8 de diciembre de 1661), aprobaba el culto de la Inmaculada Concepción ${ }^{4}$. Para 1664 la declara como patrona y protectora de España decretando su fiesta el 8 de diciembre y proclamándose esta para todos los reinos del imperio español. Más tarde Clemente XI decretó que en 1708 que la festividad de la Inmaculada Concepción era de precepto para toda la iglesia 5 .

Posteriormente, con la aparición de la virgen María a sor Catalina Labouré, hermana de la Caridad, el día 27 de noviembre de 1830 en el convento situado en la rue $d u$ Bac de París influyó en la futura definición dogmática. En esa visión a Santa Catalina se apareció la virgen bajo la advocación de la Inmaculada Concepción: la figura de maría estaba rodeada por una leyenda: “Oh María sin pecado concebida, rogad por nosotros que recurrimos a vos"6. En esta aparición recibió, entre otros, el mensaje de hacer acuñar la "Medalla Milagrosa", que entre 1832 y 1836 ya había logrado la distribución de 36 millones de medallas, creando un ambiente de devoción y piedad hacia La Inmaculada Concepción?

El papa Pío IX, en el año de 1848-1854 constituyó una comisión de 20 teólogos para estudiar este dogma y realizó varias consultas ${ }^{8}$. De ahí que, Pío IX mediante la bula

\footnotetext{
${ }^{2}$ Flórez, Gloria Cristina. Advocaciones Mariana de Gloria (Lima: Universidad Nacional Mayor San Marcos, Editorial San Lorenzo del Escorial, 2012), p. 1123.

${ }^{3}$ Flórez, Gloria Cristina, Op Cit., p. 1124.

${ }^{4}$ Sánchez, Valentín Soria. "Historia de las fiestas de la Inmaculada Concepción en Extremadura", La Inmaculada concepción en España: Religiosidad, arte y cultura (España: Ediciones Escuerialenses, 2005), pp. 577-579.

${ }^{5}$ Flórez, Gloria Cristina, Op Cit., pp. 1123-1127.

${ }^{6}$ Basteros de Eleizalde, Juan Luis. "La Inmaculada Concepción en los siglos XIX y XX", en Anuario de Historia de la Iglesia, vol. XIII, núm. 1, 2004, p. 80.

${ }^{7}$ Ibid.

${ }^{8}$ Pío IX solicitó el voto sobre el mismo tema a una Comisión de 8 cardenales y cinco consultores. Finalmente, el 2 de febrero de 1849 promulgó la encíclica Ubiprimum pidiendo la opinión sobre la conveniencia de la definición dogmática de la Inmaculada Concepción a todo el episcopado católica. Basteros De Eleizalde, Luis. "La Inmaculada Concepción en los siglos XIX y XX", Op Cit., p. 81
} 
Innefabilis Deus ${ }^{9}$ el 8 de diciembre de 1854 definió como dogma La Inmaculada Concepción de María ${ }^{10}$, una creencia obligatoria para todos aquellos que reconocieran la autoridad espiritual de Roma. A partir de la definición dogmática, surge un momento de esplendor mariano en el pueblo cristiano. De hecho, a la declaración dogmática se une la aparición de Lourdes en 1858, en la que, según la vidente Sta. Bernardette Sourbirous, la virgen se presentó como la Inmaculada Concepción ${ }^{11}$.

Ahora bien, la creación por parte de Pío IX (1854) del dogma de la Inmaculada Concepción de María, generó el incremento a la devoción mariana por parte de los feligreses católicos. Asimismo, las diferentes órdenes religiosas con tendencia mariana, apoyaron e implementaron toda una serie de actividades para su difusión. Es necesario aclarar, que este dogma proclama que María desde el momento de su concepción estuvo libre todo pecado original por la gracia de dios, el cual debía transmitirse por ser descendiente de Adán y Eva. No debe confundirse con su maternidad virginal que sostiene que Jesús fue concebido por obra del espíritu santo y sin intervención de varón, es decir que estuvo virgen antes, durante la gestación y después.

\section{La Romanización y el impulso de la devoción mariana en Colombia, Siglo XIX y XX}

Con la creación por parte de Pío IX (1854) del dogma de la Inmaculada Concepción, se generó el incremento a la devoción y culto de María por parte de los feligreses católicos. Según el historiador William Elvis Plata Quesada, con el dogma y la encíclica papal Quanta Cura y su decálogo El Syllabus (1864), se inició el proceso de romanización de la iglesia católica ${ }^{12}$ que tuvo su punto álgido en el Concilio Vaticano I, celebrado entre 1869 y 1870 , en el cual se aprobó el dogma de infalibilidad pontificia; además, se realizaron cambios en las expresiones y representaciones religiosas. Por un lado, se llevó a cabo un redescubrimiento de Jesús (encarnación de Dios o Verbo encarnado). Asimismo, las figuras y las concepciones de maría adquirieron unos rasgos europeos uniformes que fueron implantados en el resto del mundo católico, por encima de las tradiciones populares ${ }^{13}$. Igualmente, se impulsó la celebración periódica de sínodos provinciales, arquidiocesanos y diocesanos ${ }^{14}$, enfocados en la unidad de la

\footnotetext{
${ }^{9}$ Pío IX. Encíclica papal Ineffabilis Deus, 8 de diciembre de 1854, http://www.papalencyclicals.net/Pius09/ p9ineff.htm (27 de marzo de 2015).

${ }^{10}$ A través de esta bula el catolicismo sostiene que María Madre de Jesús, a diferencia de todos los seres humanos no fue alcanzada por el pecado original sino que, desde su concepción, estuvo libre de pecado. Warner, Marina. Tú sola entre las mujeres. El mito y el culto de la Virgen María (España: Taurus Humanidades, 1991), p. 308.

${ }^{11}$ Basteros de Eleizalde, Juan Luis. "La Inmaculada Concepción en los siglos XIX y XX”, Op Cit., p. 82.

12 Plata Quezada, William Elvis. El catolicismo y sus corrientes en Colombia decimonónica. 1850-1880, (tesis de maestría), Universidad Nacional de Colombia Bogotá, 2001, p. 235.

${ }^{13}$ Ibid.

${ }^{14}$ El I Concilio Provincial de Nueva Granada, liderado por monseñor Vicente Arbeláez, arzobispo de Bogotá, entre el 29 de junio al 8 de septiembre de 1868 de la Nueva Granada. En 1870 se celebra el sínodo de la Arquidiócesis de Bogotá; mientras que en la diócesis de Pamplona se realizó el sínodo de 1872, posteriormente en el siglo XX se realizaron varios en diferentes diócesis. Vega Rincón, Jhon Janer. "El
} 
iglesia, mantener la disciplina del clero y fomentar la piedad en los fieles. De hecho, estos concilios fueron clave para la reorganización de los seminarios y a la reforma y arribo de nuevas comunidades religiosas de marcada concepción mariana (Jesuitas, Hermanas de la Presentación, Carmelitas, Vicentinos, Redentoristas, Salesianos(as), Claretianos, Vicentinas, San Juan de Dios, entre otras).

Entre las décadas de 1870 a 1880 el sector del catolicismo tradicionalista e intransigente, pretendió utilizar la encíclica y el decálogo para contrarrestar al Olimpo Radical (18631877) y su reciente Reforma Educativa (1876-1877), a favor de una alianza entre la institución eclesiástica y el partido conservador, que se materializará en el periodo denominado de Hegemonía Conservadora (1886-1930), con el que se afianza lo que denomina el historiador José David Cortes Guerrero El Régimen de Cristiandad ${ }^{15} \mathrm{y}$ donde se estrechan los vínculos entre Iglesia y Estado. Toda esta maquinaria se verá plasmada en la Constitución de 1886, la firma del Tratado el 31 de diciembre de 1887 entre Colombia y el Vaticano, la asistencia de varios obispos colombianos al Concilio Plenario Latinoamericano en $1899^{16}$ en Roma, la Consagración del Sagrado Corazón de Jesús el 20 de julio de 1902 y la celebración del primer congreso mariano de carácter nacional, que tuvo como fin la coronación de la virgen de Chiquinquirá como patrona y reina de Colombia en $1919^{17}$.

Estas circunstancias, posibilitaron la implementación del catolicismo tradicionalista de corte intransigente, ultramontanista e integrista al interior de la institución eclesiástica colombiana a finales del siglo XIX y durante la primera mitad del siglo $\mathrm{XX}^{18}$. Es necesario aclarar, que la corriente integrista o en otras palabras contrario a la posibilidad de dejarse reducir únicamente a actividades de culto y a convicciones religiosas, se muestra dispuesta a edificar una sociedad cristiana bajo la enseñanza y la conducta de la iglesia, afectando todos los componentes del sistema religioso ${ }^{19}$.

Sínodo diocesano de Nueva Pamplona de 1872 y la disciplina sacerdotal", en Anuario de Historia Regional $y$ de las Fronteras, vol. XVII, núm. 1, Bucaramanga, Universidad Industrial de Santander, enero-junio de 2012, pp. 139-141.

${ }^{15}$ Cortés Guerrero, José David. "Regeneración, Intransigencia y Régimen de Cristiandad”, en Revista Historia Crítica, núm. 15, Bogotá, 1997, pp. 3-12.

${ }^{16}$ Pazos M., Antón. "El iter Concilio Plenario Latino Americano de 1899 o la articulación de la Iglesia latinoamericana", en AHIg., núm 7, Pamplona, Universidad de Navarra, 1998, pp. 185-206. También, Arboleda, Carlos. "El pluralismo religioso en Colombia", en Ortiz, Javier (Dir), Ganarse el cielo defendiendo la religión. Guerras Civiles en Colombia, 1840-1902. Bogotá: Unibiblos, 2005, pp. 491-492.

${ }^{17}$ Plata Quezada, William Elvis, et al. Conventos Dominicanos que Construyeron un país. Arquitectura Dominicana, fe y sociedad en la Nueva Granada Siglos XVI-XIX (Bucaramanga: Universidad Santo Tomás, 2010), p. 325.

${ }^{18}$ Gracias a los trabajos de los historiadores se ha podido avanzar en el estudio de la corriente tradicionalista, y en especial de la intransigencia y el integrismo por parte del clero colombiano. Entre los más importantes: Rodolfo Ramón de Roux, José David Cortes, Christopher Abel, Ricardo Arias, María Teresa Cifuentes, Gloria Mercedes Arango, Carlos Arboleda Mora, Luis Javier Ortiz Mesa, Helwar Figueroa, Tomas Williford, Ivonne Rodríguez Calderón y Sergio Armando Cáceres Mateus, entre otros.

${ }^{19}$ Cifuentes Traslaviña, María Teresa y Florián Navas, Alicia. "El Catolicismo social: entre el Integralismo y la Teología de la Liberación”, en Bidegain Ana María (ed.), Historia del Cristianismo en Colombia, Corrientes y Diversidad. Bogotá: Taurus, 2005, p. 321. 
De esta manera, la proclamación del dogma de la Inmaculada Concepción en 1854 brindó las herramientas para implementar la romanización en América Latina durante la segunda mitad del siglo XIX, hasta la celebración del Concilio Vaticano II. Es decir, la relación entre la proclamación de este y el soporte que le dio al proceso de romanización es indiscutible, se constituyó en un hito, en donde el contexto confluyó para el aprovechamiento a nivel político y religioso del esplendor del culto a la virgen María. Por esta razón la proclamación de Pío X en 1920 de la virgen de Guadalupe como patrona de América Latina y coronada por Pio X en 1933 como patrona del continente americano; sin contar con la celebración de congresos marianos, que en el caso de Colombia se celebraron en 1919 y 1946, y tuvieron como resultado la coronación de la Virgen de Chiquinquirá y la Virgen del Carmen.

\section{Puesta en marcha y celebración del Primer Congreso Nacional Mariano, 1908-1919}

Entrado el siglo XX La Orden de Predicadores durante aproximadamente 12 años de trabajo logra que el santuario de Chiquinquirá fuera un símbolo de peregrinación y culto mariano a nivel nacional. La campaña comienza en 1908 por iniciativa de Fr. Vicente María Cornejo y el Prior Fray José Ángel Lombana, este último, nombrado provincial de los dominicos en Colombia, quien gracias a sus influencias en el Vaticano y con la fundación de varios periódicos, logró aumentar la devoción mariana (Veritas y El Cruzado, entre otros $)^{20}$. Asimismo, llevaron a cabo la renovación del santuario ${ }^{21}$, además de enviar una copia del cuadro en misión por diferentes departamentos ${ }^{22}$. Finalmente, el 9 de enero de 1910 obtiene el Decreto de Pío X, gracias al trabajo diplomático del embajador de Colombia, José María Rivas Groot ${ }^{23}$. Para el 20 de julio de 1914 los dominicos entregan el plan para la coronación de la Virgen del Rosario de Chiquinquirá. En efecto, esto repercutiría al interior de la Orden de Predicadores, pues el 11 de marzo de 1918 visitó el Santuario el maestro general fray Luis Theissling ${ }^{24}$. Ya para el 7 de junio de 1918 el obispo de Tunja, Eduardo Maldonado Calvo, ordenó el traslado hacia Bogotá del cuadro. Esto produjo una asonada, pues quedó la sensación entre los feligreses que habían vendido la imagen a Bogotá ${ }^{25}$. Sin embargo, la calma se restableció después de decretarse la coronación del Primer Congreso Nacional Mariano.

\footnotetext{
${ }^{20}$ Figueroa Salamanca, Helwar. "Intransigencia Católica en Colombia durante los años treinta”, en Revista de Ciencias Sociales y Religión Asociación de Cientistas Sociales de la Religión de Mercosur, Año 7, Porto Alegre, 2005, p. 112.

${ }^{21}$ En julio de 1914 los padres dominicos iniciaron los trabajos para reformar el templo de Nuestra señora del Rosario de Chiquinquirá.

${ }^{22}$ Boyacá, Santander, Cundinamarca, Caldas, Huila, Tolima y Antioquia.

${ }^{23}$ Cornejo \& Mesanza. El minucioso relato sobre La coronación de Nuestra Señora del Rosario de Chiquinquirá (Chiquinquirá: 1919), pp. 219-233; Londoño Botero, Rocío. "La Virgen de Chiquinquirá símbolo de identidad Nacional”, en Revista de Sociología, núm. 32. Bogotá, UNAL, 2009, pp. 83-94.

${ }^{24}$ Castaño Rueda, Julio Ricardo. Nuestra Señora del Rosario de Chiquinquirá, historia de una tradición (Bogotá: Fundación Editorial Epígrafe, 2005), pp. 98-99.

${ }^{25}$ Ibid., p. 99.
} 
Entre el 28 de junio y el 8 de julio de 1919 como actividad principal se realiza la Sexta peregrinación de la virgen del Rosario de Chiquinquirá hasta Bogotá, siendo escoltada por el Batallón Soublette. El cuadro con la numerosa peregrinación pasó por las poblaciones de Simijaca, Susa, Fúquene, Ubaté, Sutatausa, Nemocón, Cogua, Zipaquirá, Cajicá, Chía, Usaquén y Bogotá (Iglesia Nuestra Señora de Lourdes en Chapinero y Catedral Primada de Bogotá) ${ }^{26}$. Finalmente el 9 de Julio de 1919 fue coronada como reina y patrona de Colombia. La ceremonia tuvo lugar en la Plaza de Bolívar de Bogotá siendo presidida por el presidente de la República de Colombia, Marco Fidel Suárez ${ }^{27}$. Además, contó con la presencia del Nuncio Apostólico Enrique Gasparri, los presbíteros Jenaro Jiménez y Eduardo Díaz y el obispo de Tunja Eduardo Maldonado, este último encargó de coronar a la virgen y al niño ${ }^{28}$.

Luego de haberse realizado el evento, Ismael Perdomo, Arzobispo de Bogotá a través de la Pastoral Colectiva de 1919, enuncia el apoyo de la Conferencia Episcopal para la construcción de un monumento a la Virgen en el cerro de Guadalupe como recuerdo del primer congreso mariano de Colombia ${ }^{29}$. Asimismo, el episcopado realiza un pronunciamiento frente a la trascendencia del evento y la importancia para Colombia de haber pactado el voto nacional a la virgen como madre y patrona de Colombia:

[...] Ahora bien, debiéndose dejar oír nuestra voz a raíz de ese acontecimiento grandioso [...] hemos juzgado lo más conveniente el que nuestra instrucción verse sobre el amor y devoción a la que poco a aclamado nuestra nación como su Reina y a la que todos invocamos como nuestra dulce y celestial Madre. [...] El amor a nuestras madres es el primero que nace en el corazón humano; y aunque aparezca otro durante la vida, aquel se diferencia de todos y los vence en intensidad y duración [....].

Las anteriores consideraciones, tan conocidas de todos nuestros hijos en el señor, fueron las que nos determinaron, en la última conferencia episcopal, a decretar el Congreso Mariano, a fin de promover por este medio el aumento del culto de María, [...] que el amor a nuestra bendita madre creciera en nuestra patria, para lograr como fin principalísimo la conservación de la fe cristiana amenazadas por multitud de errores difundidos por la mala prensa, la conversión de muchas almas extraviadas, y la perseverancia en el bien de las que están firmes en la piedad y en las buenas costumbres ${ }^{30}$.

Casi una década después, el 18 de agosto de 1927, el Papa Pío XI le dio al santuario de Chiquinquirá el título de Basílica Menor, ceremonia que se celebró el 9 de julio de 1928, a la cual asistió Pablo Giobe, Nuncio Apostólico, el Arzobispo Ismael Perdomo y el presidente de la república de ese periodo, Miguel Abadía Méndez ${ }^{31}$.

\footnotetext{
${ }^{26}$ Londoño Botero, Rocío. "La Virgen de Chiquinquirá símbolo de identidad Nacional”, Op Cit., pp. 83 -94.

${ }^{27}$ Castaño Rueda, Julio Ricardo, Op Cit., pp. 91-92.

${ }^{28}$ Coronación Canónica de la Imagen y su ocurrir histórico en el siglo XX y XXI, http://www. virgendechiquinquira.com/index.php?option=com_content\&view=article\&id=44\&Itemid=1 $(7$ de abril del 2015).

${ }^{29}$ Coronación Canónica de la Imagen y su ocurrir histórico en el siglo XX Y XXI...

30 "Monumento en Guadalupe (1919)", en Conferencias Episcopal de Colombia, Tomo I, 1908-1953 (Bogotá: Editorial el Catolicismo, 1956), p. 270.

31 "Pastoral Colectiva de 1919", Op Cit., p. 636.
} 
A continuación, se analiza el aumento de la devoción mariana en la República Liberal (1930 -1946), situación que se observa por la participación de sacerdotes y laicos en una serie de actividades a través de la Acción Católica Colombiana (A.C. C.)

\section{La Acción Católica Colombiana y el Segundo Congreso Mariano (1933-1946)}

En esta segunda parte se explica la creación de la A. C. C. ${ }^{32}$ (1933), la dirección de las organizaciones católicas a través del Asistente Eclesiástico y la inserción del laico en diversas actividades de la Iglesia, sobre todo nos enfocaremos en describir el apoyo que brinda en lo referente al culto mariano. Igualmente, se narra el proceso que llevó a cabo las directrices nacionales de la A. C. a través de las diócesis para lograr la organización del congreso en diferentes parroquias del país (1939-1942). Sin embargo, es necesario señalar que el congreso no fue aprobado por parte de Pío XII para el año de 1942, aplazándolo hasta julio de 1946.

\section{La Acción Católica Colombiana y culto a la Virgen María}

El nacimiento de la A. C. en Europa se observa tempranamente durante el siglo XIX ${ }^{33}$. Muchas de ellas fueron implementadas como herramientas de diferentes corrientes político-religiosas al interior de la iglesia católica, que fueron puestas en marcha por las órdenes religiosas. Es más, solo hasta el siglo XX, se observa el nacimiento, difusión y ejecución en masa, de la A. C. en la mayoría de países de América Latina ${ }^{34}$. En cada uno de estos países se realizaron congresos eucarísticos y congresos marianos a lo ancho y largo del territorio, de manera que se proclamará el Reinado de Cristo y de la virgen María.

En este sentido, La Conferencia Episcopal de Colombia en la reunión de julio de 1933 decretó la instauración de la A.C ${ }^{35}$, según lo propuesto por Pio XI en la encíclica

\footnotetext{
${ }^{32}$ Coronación Canónica de la Imagen y su ocurrir histórico en el siglo XX y XXI...

${ }^{33}$ Es necesario aclarar que existen dos tipos de organizaciones dentro de la A. C. En primera instancia la A. C. General (Hombres Católicos, Mujeres católicas, Juventud Católica Femenina), que era manejada por círculos integristas e intransigentes de la jerarquía eclesiástica colombiana. En segunda instancia esta La A. C. Especializada, conformada fundamentalmente por asociaciones juveniles de diferentes edades y fines (la JOC- Juventud Obrera Católica o Yocismo, JUC -Juventud Universitaria Católica y JEC- Juventud Estudiantil Católico). Muchas de estas organizaciones Especializadas entre 1938-1939 se distanciaron poco a poco de las corrientes más integristas del catolicismo presentes en el proyecto de A. C. General y se constituyeron en vehículos de formación laical sindical. Dicha decisión de los dirigentes en la década del 40 les va a costar la expulsión de estos.

${ }^{34}$ Irlanda (1823), Alemania (1846), Bélgica (1863), Italia (1865), Francia (1871), y Holanda (1903). Escartín Celaya, Pedro. Apuntes para la Historia de la Acción Católica en España, http://www.accioncatolicageneral. es/index.php?option=com_docman\&task=doc_view\&gid=481, (30 de agosto del 2011).

${ }^{35}$ Cuba (1929), Argentina y Chile (1931), Paraguay (1932), Colombia (1933), Uruguay (1934), Ecuador y Perú (1935), Bolivia (1938). Dussel, D. Enrique. Historia de la Iglesia en América Latina (Bogotá: USTA, 1984). E. Dussel, et al. Historia General de La Iglesia en América Latina T. IX Cono Sur (Argentina, Chile, Uruguay y Paraguay) (España: CEHILA, Ediciones Sígueme S. A, 1994). E. Dussel, et al. Historia General de la Iglesia en América Latina Tomo VIII (Perú, Bolivia y Ecuador) (Salamanca: CEHILA, Ediciones Sígueme, 1987).
} 
Quadragesimo Anno (1931) ${ }^{36}$. De hecho, la ceremonia estuvo a cargo del Arzobispo de Bogotá Ismael Perdomo, que junto al chileno Jorge Fernández Pradel ${ }^{37}$, especialista en el tema, del 2 al 4 de enero de 1934 se reunieron con 130 sacerdotes de varias diócesis para explicarles el funcionamiento de la organización y en especial el papel que cumplía el sacerdote en la dirección de las organizaciones católicas (Asistente Eclesiástico $)^{38}$.

Para el mes de junio de 1934 la A. C. C. creó "La Liga de Avemaría”, una "Cruzada Nacional de Oraciones" 39 que tenía una serie de objetivos que buscaban incrementar la fe en los creyentes por medio del milenarismo y la salvación del pueblo colombiano; además, de una actitud vigilante y de censura ante publicaciones, folletos o la prensa de corte liberal, comunista o protestante, la cual era considerada "mala, impía e inmoral" " Conforme a esa idea, el "apóstol", "asociado" o "laico", que repetía esta oración se comprometía a "no comprar ni leer jamás, sin graves razones, ninguna publicación, diario, revista, libro o folleto que atacará a la religión o la moral"41.

Posteriormente, en la medida que la A. C. iba creciendo, en diferentes diócesis y parroquias del país, se fueron llevando a cabo congresos, asambleas y semanas sociales $^{42}$. De hecho, del 2 al 6 de febrero de 1937 se realiza en Medellín la primera Asamblea Nacional de Asistentes Eclesiásticos diocesanos y que según palabras del Pbro. Antonio Jaramillo de la arquidiócesis de Medellín, tenía como objeto "formar la Unidad de pensamiento de este movimiento"43. No obstante, según nuestro objeto de

\footnotetext{
36 “Acuerdos Sobre Acción Católica”, Op Cit. pp, 1-30.

${ }^{37}$ A través de esta encíclica se infunde la restauración del orden social y la creación de la Acción Católica, como un medio para llegar al Reinado de Cristo. Se inicia, así una inserción del laico en los proyectos de la Iglesia, a través del culto y actividades, y al mismo tiempo la conformación de una militancia católica que debía hacerle contrapeso a los ideales revolucionarios del momento. Cáceres Mateus, Sergio Armando. "La Acción Católica Colombiana y la resistencia al proyecto de laicización del partido liberal, 1934-1942”, en: Plaza, William Elvis (ed). El Hecho Religioso en Perspectiva Regional (Bucaramanga: UIS, 2013), p. 288.

${ }^{38}$ Nació en Chile el 26 de septiembre de 1879, estudio en Santiago de Chile, en España, Holanda en Bélgica, etc. Se ordenó sacerdote en 1912. Autor de varios artículos y publicaciones. Durante la dictadura de Alessandri 1932-1938 fue exiliado en Colombia. Bidegain de Uran, Ana María. Iglesia, pueblo y política. Un estudio de conflictos de intereses. Colombia, 1930-1955 (Bogotá: Pontificia Universidad Javeriana, Facultad de Teología, 1985), p. 201.

${ }^{39}$ En una primera instancia las funciones del Asistente Eclesiástico eran las siguientes: “a) Le corresponde formar la conciencia cristianas, la conservación de la moral cristiana y la administración de los sacramentos. b) Determinar el espíritu con que se debía proceder, indicaba los escollos que se debían evitar; además de dar la voz de alerta cuando se encontraba de frente con el error. c) Ser el representante de la autoridad eclesiástica. Posteriormente estás se ampliarían en 1937 con la Primera asamblea de Asistentes Eclesiásticos realizada en Medellín. "El Asistente Eclesiástico en la A. C", en Revista Oficial de la A.C.C, Año I, núms. 3 y 4, Bogotá, marzo-abril, 1934, pp. 61-68.

40 "Recitar cada día un Padre Nuestro y un Ave María, con la invocación de Nuestra Señora de Colombia, rogad por nosotros".

41 “Liga de Ave María”, en Revista Oficial de la A.C.C, Año I. núm. 7, Bogotá, julio 1934, p. 175.

${ }^{42}$ Ibíd. pp. 175-176.

${ }^{43}$ Desde 1935 a 1938 se crearon toda una serie de actividades al interior de la Iglesia Católica. Congresos Eucarísticos: Primer y Segundo Congreso Eucarístico (Bogotá y Medellín 1935). Asimismo las Semanas Sociales y Sacerdotales de Garzón (Huila) (1936), Ibagué (1936) Bogotá y Medellín (1938). Cáceres Mateus, Sergio Armando. "La Acción Católica Colombiana y la resistencia al proyecto de laicización del
} 
estudio lo más importante de esta reunión, es la función que va a asumir el Asistente Eclesiástico para emprender una campaña con los integrantes de la A. C. y de la sociedad en general, para forjar una mayor devoción a la Inmaculada Concepción y a la Virgen del Rosario de Chiquinquiráa ${ }^{44}$. Es decir, desde este año la jerarquía eclesiástica estaba creando las bases y actividades necesarias para llevar a cabo el segundo congreso mariano.

Es necesario aclarar, que la A. C. fue un intento de la jerarquía eclesiástica de introducir al laico al interior de la iglesia, sobre todo en lo referente al culto mariano y a la expansión de las organizaciones católicas. Sin embargo, este hecho generó según la experiencia de varios investigadores un paternalismo excesivo y un mecanismo de control por parte de los sacerdotes, lo cual produjo que en algunas de estas asociaciones los laicos no tuvieran libertad para tomar decisiones, situación que en ocasiones sellaría la muerte de estas ${ }^{45}$.

\section{Organización del Segundo Congreso Mariano en Colombia 1939-1942}

El icono de la virgen del Rosario y la Inmaculada Concepción fue retomado por la A. C. C. entre 1939 -1942, como un mecanismo de integración e intermediación, y como un instrumento en contra del protestantismo, el laicismo, el liberalismo, el comunismo y cualquier ideología que contrarrestará el "Reinado de Cristo en Colombia". Para lograr este objetivo, se realizaron toda una serie de actividades encaminadas a la celebración del segundo congreso nacional mariano en el año de 1942, como se explica a continuación.

\section{Primeras actividades para consagrar la Acción Católica Colombiana a la Virgen María}

En la Revista Acción en el mes de mayo de $1939^{46}$ aparece un artículo en el que se retoma algunos postulados de finales del siglo XVII y principios del siglo XVIII del sacerdote Francés Luis. M. Grignion de Montfort ${ }^{47}$, en el que se afirma la necesidad que

\footnotetext{
partido liberal, 1934-1942", Op Cit. pp. 310-316.

${ }^{44}$ Ibid.

${ }^{45}$ Entre las conclusiones más relevantes: a) Direccionar una campaña con la A. C. y la sociedad en general a favor de la devoción de la Virgen María y Nuestra Señora del Rosario de Chiquinquirá. b) Debían difundir y promover la celebración de Semanas Sindicales, Nacionales y Diocesanas. Esto tenía como fin la creación de sindicatos católicos y la conformación de federaciones sindicales. c) Trabajar por la fundación de escuelas propagandistas sindicales de la A. C. C. d) Instruir al pueblo sobre las doctrinas opuestas a la enseñanza cristiana. e) Implementación de publicaciones católicas. f) Establecer en cada diócesis una campaña en pro de la decencia de los espectáculos cinematográficos. Además de apoyar a la Sociedad Industrial Cinematográfica (S.I.C) empresa al servicio de la A. C. C. "Conclusiones de la Primera asamblea de Asistentes Eclesiásticos”, en Revista Acción, Año VI, núm. 56, Bogotá, abril 1937, pp. 24-25.

${ }^{46}$ El Caso más representativo es la Juventud Obrera Católica (J.O.C.) Cáceres Mateus, Sergio Armando. "La Acción Católica Colombiana y la resistencia al proyecto de laicización del partido liberal, 1934-1942", Op Cit., pp. 285-328.

${ }^{47}$ Grignion de Montfort, Luis M. "Los Apóstoles de los últimos tiempos”, en Revista Acción, Año: VI, núm. 57, Bogotá, mayo 1939, p. 129.
} 
tienen todos los apóstoles y católicos de servir y reconocer la soberanía de la virgen María como madre de Dios. De manera que, al reconocer la grandeza de la virgen, por un alado era utilizada como mediadora con dios y por otro los apóstoles y seguidores tendrían un arma a favor para vencer a los enemigos de la Iglesia:

Y será así, sin duda [...] conocerán las grandezas de esta Virgen Soberana y se consagrarán completamente a su servicio como súbditos suyos y esclavos de su amor; saborearán sus dulzuras y sus bondades maternales, y la amarán con la ternura de hijos muy amados [...] y recurrirán a ella en todo como a la mejor abogada y mediadora para con Jesucristo; sabrán que María es el medio más seguro, más fácil, más corto y perfecto camino para ir a Jesucristo, y se entregarán a Ella en cuerpo y alma, sin partición, para ser suyos del mismo modo que Jesucristo". [...] estos servidores [....] serán flechas agudas en la mano de la poderosa María para herir a los enemigos de Dios [...] todos aquellos quienes sean enviados de parte del Altísimo serán verdaderos apóstoles de los últimos tiempos, a quienes el Señor de las virtudes dará la palabra y la fuerza para obrar maravillas y para ganar maravillosos despojos a sus enemigos. ${ }^{48}[\ldots]$.

De manera que, todo católico debía profesar y reconocer la grandeza de la virgen; además, se transfiguraba en un estandarte en contra de sus diversos enemigos (liberalismo, comunismo y protestantismo), este último que era catalogado públicamente por la jerarquía eclesiástica de secta o herejía al mejor estilo del Concilio de Trento y la contrarreforma católica del siglo $\mathrm{XVI}^{49}$.

Por otro lado, entre el 21 y 27 de mayo de 1939, se realizó una Semana de estudios en los Seminarios Mayor y Menor de la ciudad de Bogotá, en donde se llevaron a cabo distintas actividades ${ }^{50}$. En ambos seminarios se ejecutaron conferencias por parte de algunos miembros de la jerarquía eclesiástica, seglares y seminaristas, enfocadas en temáticas relacionadas con los objetivos, medios y fines de la A. C. Por otro lado, la junta de estudios del seminario menor, tomó como decisión nombrar como "patrona de la Junta a la Santísima Virgen María Reina de los Apóstoles" "51. Además, se realizó en la iglesia parroquial de Las Nieves de Bogotá, la consagración de la A. C. a la virgen $^{52}$. Esta actividad fue precedida por el Arzobispo de Bogotá, Ismael Perdomo y por el Asistente Eclesiástico Nacional de la A. C. C., Juan Manuel González Arbeláez

\footnotetext{
${ }^{48}$ Luis María nació en Monfort, Francia el 31 de enero de 1673, en el seno de una familia numerosa. [...] desde joven tenía una gran devoción a la Eucaristía y a la Virgen María. [...] en 1693, a los 20 años, siente el llamado a consagrar su vida a Dios a través del sacerdocio. [...] el 5 de junio de 1700, con 27 años de edad fue ordenado sacerdote. Escogió como lema de su vida sacerdotal "Ser Esclavo de María". [...] un año antes de su muerte el padre Monfort fundo dos congregaciones: Las Hermanas de la Sabiduría, dedicadas al trabajo del Hospital y la instrucción de niñas pobres, y la Compañía de María, dedicada a las Misiones. [..] Murió en Saint Laurent sur Sevre el 28 de abril de 1716, a la edad de 43 años. Biografía de Luis M Grignion de Monfort, http://www.corazones.org/santos/luis_montfort.htm (8 de enero de 2011).

${ }^{49}$ Grignion De Montfort, Luis M. "Los Apóstoles de los últimos tiempos”, Op Cit., pp. 129-130.

${ }^{50}$ Echavarría Uribe, Otoniel. "La Herejía. Estigmatización del Protestantismo en la Diócesis de Nueva Pamplona, 1868-1943”, (tesis pregrado), Bucaramanga, Universidad Industrial de Santander, 2010.

51 "Semana de A.C. en el Seminario Mayor y Menor de Bogotá", en Revista Acción, Año VI, núm. 58, Bogotá, junio 1939, pp. 193-195.

${ }^{52}$ Ibid.
} 
y demás asistentes y miembros de la A. C. Terminada la ceremonia se llevó a cabo una procesión dentro de la Iglesia con una copia del cuadro de la virgen del Rosario de Chiquinquirá ${ }^{53}$. Es decir, rápidamente la $\mathrm{A}$. C y la jerarquía eclesiástica generaron toda una serie de dinámicas que tenían como objeto la consagración de la virgen en las variadas asociaciones católicas.

\section{Preliminares del Segundo Congreso Nacional Mariano}

La primera actividad que se realizó para la preparación del segundo congreso mariano en Colombia, fue a partir del 10 de abril de $1940^{54}$, fecha donde la Conferencia Episcopal decreta la creación de un Comité Pro Peregrinaciones a cargo del Asistente Eclesiástico Pbro. Víctor Barros Morales. Igualmente, se consolida la celebración en la ciudad de Bogotá de un congreso nacional mariano en 1942, y la celebración de peregrinaciones a santuarios, procesiones, semanas de estudio y cultos en honor a la virgen María, todo ello con el objeto de la renovación y consagración de la sociedad Colombiana a la virgen como símbolo del "Reinado de Cristo" 55 .

A causa de este decreto, el 15 de agosto de 1940 se realizó una peregrinación al Santuario del municipio de Chiquinquirá, gracias a la gestión del Comités6. El 15 de agosto salieron 700 peregrinos de la estación de Bogotá en tres trenes que tenían como destino Chiquinquirá. La logística estuvo a cargo de Hernán Vergara, Manuel José Forero, Gabriel Betancourt, Pablo Forero, Alfonso Casas Morales y Wenceslao Cabrera $^{57}$. Al llegar al destino fueron recibidos por hermandades religiosas, escuelas, colegios y numerosos vecinos de la población "quienes a la llegada entonaron el himno mariano acompañados por la banda municipal, dando en esta forma la bienvenida a los visitantes" ${ }^{58}$. Mientras tanto, en la Basílica esperaban a la peregrinación Ismael Perdomo Arzobispo Primado y Francisco Cristóbal Toro Obispo de Antioquia y Jericó. Dando inicio a la actividad, el arzobispo realizó una alocución, en la que ofrecía a la virgen del Rosario de Chiquinquirá, el imponente acto ${ }^{59}$. En seguida, un fraile dominico dio la bienvenida a los peregrinos, y les hizo una breve reseña del santuario ${ }^{60}$. Todos los concurrentes se reunieron en las naves de la basílica, para acompañar la procesión del Sacramento. De hecho, a las dos de la tarde las campanas de la basílica comunicaron que se daba inició a la procesión de la virgen por las principales calles. A las 5 de la tarde los peregrinos se estaban acomodando en los trenes para regresar a Bogotá61 .

\footnotetext{
${ }^{53}$ Ibid.

${ }^{54}$ Ibid.

55 “El porqué de las peregrinaciones Marianas Nacionales e Interparroquiales", en Revista Acción, Año VII: núm. 72, Bogotá, agosto 1940, pp. 74-75.

${ }^{56}$ Ibid.

${ }^{57}$ Rico De Herrera, Alicia. "Asociación de Señoras Católicas. Peregrinación Nacional al santuario de Nuestra Señora de Chiquinquirá”, en Revista Acción, Año VII, núm. 72, Bogotá, agosto 1940, pp. 72-73.

${ }^{58}$ Ibid.

${ }^{59}$ Ibid.

${ }^{60}$ Ibid

${ }^{61}$ Ibid.
} 
Posteriormente, el 24 de mayo de 1941, el Arzobispo de Bogotá, decretó la creación de un Comité para los preparativos del segundo congreso nacional mariano ${ }^{62}$. En la presidencia de este Comité se encontraba Juan Manuel González Arbeláez quien contaba con el apoyo de la jerarquía eclesiástica y de la A. C.C. Días después, en la ciudad de Bogotá, se llevaron a cabo dos peregrinaciones a santuarios marianos: por un lado, al santuario de La Peña, y por el otro, el del Campo ${ }^{63}$.

Para noviembre de 1941, se publicó un artículo en la Revista Acción que se titula "1942" y con el que se impartían normas para la preparación individual y colectiva del congreso ${ }^{65}$.

En febrero de 1942 el Arzobispo implementó un proyecto para organizar la clasificación de los precios y la categorización de los congresistas que asistirían: 1 . Protectores: Los que contribuyan a los gastos del congreso con una cuota no menor de $\$ 100.00$ 2. Insignes: Los que contribuyan a los gastos con una cuota no menor de $\$ 50.00$ 3. Titulares: Los que contribuyan a los gastos del congreso con una cuota no menor de \$10.00. 4. Congresistas: Los que contribuyan con una cuota no menor de $\$ 1.00$, o con el donativo del peso mensual del congreso ${ }^{66}$. Es decir, en cada una de estas categorías el socio recibía una serie de beneficios espirituales y materiales, como insignias, diplomas, publicaciones, libros de cantos, entre otros.

Del mismo modo, fue aprovechada la ocasión para realizar un cuestionario de "temas especiales" para las sesiones o asambleas de estudio. Estos temas encerraban los tópicos que se tratarían en el congreso ${ }^{67}$. Adicionalmente, miembros de la A. C. y la jerarquía eclesiástica discutían la posibilidad de realizar conferencias sobre historia, escultura, pintura, literatura y teología. Estas conferencias y algunas exhibiciones estarían enfocadas en la virgen ${ }^{68}$. Sin embargo, en ocasiones se utilizaban para llevar a cabo un proselitismo político religioso, por un lado, que intentaba imponer la presencia de la virgen en todos los espacios de la cotidianidad de las personas, y por

\footnotetext{
${ }^{62}$ Ibid.

${ }^{63}$ "Segundo Congreso Mariano nacional. Decreto Orgánico", en Revista Acción, Año VIII, núm. 83, Bogotá, julio 1941), pp. 213-214.

64 “Congreso Mariano”, en Revista Acción, Año VIII, núms. 81-82. , Bogotá, mayo-junio 1941, p. 171.

65 “1942”, en Revista Acción, (BLAA), Año: VIII, núm. 86. Bogotá, noviembre, 1941, p. 488.

${ }^{66}$ Ibid.

67 "La Reglamentación del Segundo Congreso Mariano Nacional”, en Revista Acción, núm. 89, Bogotá, febrero 1942, pp. 39-40.

${ }^{68}$ 1. María y el hogar. 2. María y los padres de familia. 3. María y el matrimonio católico. 4. María y la educación de los hijos. 5. María y el Rosario en el hogar. 6. María y la familia moderna. 7. María y el apostolado del hogar. 8. María y las lecturas. 9. María y la santidad del hogar. 10. María, reina del hogar.11. Consagración del hogar al Sagrado Corazón y a la Santísima Virgen. 12. María en los colegios católicos. 13. María y las diversiones (cine, teatros, turismo, balnearios, etc.). 14. María y la Vocación del niño al estado sacerdotal o religioso. 15. La Sagrada Familia modelo de la familia cristiana Ut dveniatregnum Christi, adveniatregnum Mariae. Consagración del Mundo a la Santísima Virgen María. 16. La propaganda protestante en Hispanoamérica (en Colombia particularmente), y necesidad de contrarrestarla por medio de una campaña integral de Acción Católica, con la bendición de María vencedora de todas las herejías. 17. Doctrinas heréticas del Teosofismo y Rosacrucismo, sobre la persona de Cristo y de la Virgen. Propagación de estos funestos errores y medios de contrarrestarlos. 18. Necesidad de instruir convenientemente al pueblo en los dogmas marianos. Ibid., pp. 40-43.
} 
otro lado, estas conferencias eran utilizadas como un mecanismo para generar un rechazo por parte de los católicos a los protestantes, liberales y los pocos comunistas colombianos que vivían en la época. Esto con el fin de mantener por parte de la institución eclesiástica el control social de una sociedad basada en la tradición y marcada en el catolicismo intransigente e integrista.

\section{Los Comités antiprotestantes y el manifiesto anticomunista}

Para los conservadores y para un grueso importante del clero, la República Liberal (1930-1946) dio apertura para la expansión protestante y pentecostal en Colombia. Situación que era interpretado como un convenio político con los Estados Unidos para apoderarse del país a través del Panamericanismo ${ }^{69}$. Esto generó que posterior a la creación de la Acción Católica en 1933 se implementara una serie de proyectos que dieron inicio a una especie de persecución contra los protestantes y el comunismo. Proceso que se daría solo hasta la década de 1940, sobre todo por el lento funcionamiento y expansión de la Acción Católica en sus inicios.

\section{Comités antiprotestantes}

Para la década de 1940 la A. C. señala como meta y consigna, luchar contra "la propaganda hereje y atea del protestantismo" ". De manera que, la jerarquía eclesiástica retomaba las afirmaciones del Concilio de Trento (1545-1563), en las que se consideraba al protestantismo como "[...] una secta perniciosa, que utilizaba las sagradas escrituras de forma insolente, además de negar la existencia de María y de los Santos y estar en constante rebelión contra Roma"71.

Está cruzada al estilo medieval se observa impregnada ideológicamente en la Pastoral de Cuaresma de 1940, en la cual Ismael Perdomo, Arzobispo de Bogotá considera que la obra del protestantismo es guiada por el demonio para entorpecer la obra de Jesucristo en Colombia y evitar la salvación de las almas ${ }^{72}$.

Posteriormente, en una publicación de la Revista Acción de mayo de 1942, aparece un artículo en el que se refiere nuevamente al protestantismo. En esta ocasión lo catalogan de ser una herejía, en la que sus dirigentes lo que pretendían era atacar los símbolos sagrados de la iglesia y negar la santidad de la virgen María: “[...] los propagandistas

\footnotetext{
${ }^{69}$ Ibid., p.43.

${ }^{70}[\ldots]$ El régimen liberal después de 1930 demostró un amplio grado de tolerancia hacia el protestantismo, [...] En consecuencia, el número de misioneros protestantes se triplicó entre 1929 y 1938; había tres periódicos protestantes en 1938; 810 niños asistían a estos colegios. en Abel, Christopher. "Misiones protestantes en un Estado Católico: Colombia en los años cuarenta y cincuenta", en Revista Análisis Político, vol. L, enero-abril, 2004, p. 10. También en López Amaya, Jeiman David. "Misiones protestantes en Colombia 1930 - 1946. Geografía política de la expansión evangélico pentecostal”, en Anuario Colombiano de Historia Social y de la Cultura, vol. XLI, núm. 2, Bogotá, UNAL, jul-dic 2017, pp. 65-103.

${ }^{71}$ Bucana, Juana B. La Iglesia Evangélica en Colombia. Una Historia (Bogotá: Buena Semilla, 1995) También en: Sierra Jiménez, Esther Sofía. "El Misionero Protestante y la práctica de evangelizaciónconversión. La Misión Alianza Evangélica en el Norte de Santander 1944-1956”, (tesis de pregrado), Universidad Industrial de Santander, 2008.

72 "Nuestra Consigna de 1940”, en Revista Acción, Año VII, núm. 72. Bogotá, agosto, 1940, p. 50.
} 
protestantes no logran sinceros afiliados a sus religiones recién inventadas; lo único que consiguen es hacer malos católicos, enseñarles a odiar al sacerdote. Todas estas herejías coinciden sólo en negar a la Virgen sus privilegios divinos y su santidad. Van contra ella"73. Por su parte, Monseñor José Eusebio Ricaurte, consideraba que para defensa del dogma católico debía prepararse la iglesia junto a los fieles para escudar a la virgen María ante la blasfemia protestante, y aumentar el culto a María, objetivos centrales del segundo congreso mariano ${ }^{74}$.

Ahora bien, durante 1944, La Conferencia Episcopal de Colombia (CEC) a través de organizaciones católicas y de la A. C. C. se propone crear Comités Antiprotestantes ${ }^{75}$ con toda una serie de mecanismos y un modelo organizacional centralizado en Bogotá, pero que se encontraba esparcido en el territorio a través de las diócesis, vicarias y parroquias, la cual tenía el objeto de luchar contra la propaganda protestante. Para este fin debían seguir e implementar una serie de estrategias que se pueden resumir en: Publicación de un boletín donde se informe de las actividades a realizar, la enseñanza del catecismo a niños y niñas, implementar "[...] la predicación al pueblo acerca de las verdades fundamentales de la fe católica, particularmente de las impugnadas por el protestantismo"76, propagar el culto de la virgen María, utilizar medios escritos y de radiodifusión para contrarrestarlos, organizar jornadas de oración para rezar en familia el rosario y generar la consagración de las familias al sagrado corazón de Jesús y la virgen María. Asimismo, se exigía llevar a cabo un censo de protestantes a través de un modelo de planilla implantado con fines estadísticos ${ }^{77}$. Para finalizar, se hace una campaña contra los misioneros protestantes, denominándolos falsos profetas "que vienen a vosotros con vestidos de ovejas, mas por dentro son lobos rapaces"78.

De hecho, para 1951 la CEC, crea la Defensa de la Fe y los Comités Antiprotestantes, propuesta muy parecida a la de 1944. Sin embargo, tenía algunos cambios, ya que en esta ocasión se propone "una campaña durante una semana contra la herejía protestante en radio y prensa ${ }^{79} \mathrm{y}$ la excomunión a católicos por tener acercamiento y editar sus libros" $"$.

Para concluir este apartado, la jerarquía eclesiástica influyo directamente para que la A.C.C. y demás organizaciones católicas entre 1940 y 1950 implementaran una serie de acciones para contrarrestar la penetración protestante en Colombia. Para realizar

\footnotetext{
${ }_{73}$ Pastoral Colectiva en 1940. Ismael Perdomo, en: Conferencias Episcopales de Colombia 1908-1956. (Bogotá: Editorial el Catolicismo, 1956), p. 431.

${ }^{74}$ Ricaurte, José Eusebio. "La Virgen Poderosa es la defensora de la Iglesia", en Revista Acción, Año IX. núm. 92, Bogotá, mayo de 1942, p. 119.

${ }^{75}$ Ibid., p, 119.

76 “Comités Antiprotestantes (1941)", en Conferencias Episcopales de Colombia (1908-1956), Tomo I, (Bogotá: Editorial El Catolicismo, 1956), pp. 161-162.

${ }^{77}$ Ibid.

78 “Comités Antiprotestantes (1944)”, Op Cit., pp. 161-162.

79 "Pastoral Colectiva (1944)", Op Cit., p. 443

80 “Defensa de la Fe. Comités Antiprotestantes (1951). Conferencias Episcopales de Colombia (1908-1956), Tomo I (Bogotá: Editorial El Catolicismo, 1956), p. 164.
} 
este fin, consideraban que para combatir y detener la expansión del protestantismo, era necesario organizar actividades que acrecentaran la devoción y culto a la virgen María.

\section{Manifiesto anticomunista}

Al interior de la iglesia católica colombiana, especialmente los sacerdotes de zonas rurales se manifestaron rápidamente durante las primeras décadas del siglo $\mathrm{XX}$ en contra del socialismo y del comunismo, como lo demuestra el historiador Helwar Figueroa $^{81}$. Sin embargo, solo hasta 1944 la Conferencia Episcopal de Colombia realizó una intervención a través de un documento denominado "Comunismo. Manifiesto de Lucha Anticomunista" $\$ 2$, el cual trata sobre el problema social que enfrentan los trabajadores y "los pobres" y de cómo la iglesia católica a través de la encíclicas Rerum Novarum de León XII (1891) y Quadragesimo Anno de Pío XI (1931) impulsó la creación en América Latina de la Acción Católica, "única doctrina salvadora, en la que tiene que inspirarse cualquier programa de reconstrucción social". Asimismo, advierte que el comunismo ha sido condenado "[...] en repetidas veces por la suprema autoridad de la iglesia, a causa de su carácter materialista y ateo, y por ser opresor de los derechos de la persona, de la familia y de la sociedad"\$3. Finalmente, el comunicado advierte del peligro comunista que debe enfrentarse el país: "[...] deben tener en cuenta los sacerdotes que el problema actual más grave de Colombia no está precisamente en el pequeño número de adherentes al partido comunista, sino en la inmensa masa que todavía se llama liberal, pero que está influenciada por idea y jefes comunistas, muy especialmente la CTC, profundamente hostil a la Iglesia ${ }^{84}$. Es decir, la preocupación que tenía el clero era el manejo que tenían los comunistas de las masas que pertenecían a los sindicatos (CTC).

Luego de los sucesos del 9 de abril de 1948 en la que se perpetró la muerte de Gaitán y ocurrieron los diferente brotes de violencia, según los historiadores Ricardo Arias y Helwar Figueroa se reproduce la versión del grueso del clero, los conservadores y de los Estados Unidos, en la cual la responsabilidad de los hechos era de los comunistas ${ }^{85}$.

\section{Normas para la Celebración de Congresos Marianos}

El 20 de enero de 1942 Juan Manuel González Arbeláez, asistente nacional de la A. C. C. envió una carta a cada una de las parroquias, vicarias del territorio,

\footnotetext{
${ }^{81}$ Ibid.

${ }^{82}$ En la pastoral del 2 de febrero de 1926, Builes sienta cátedra sobre el socialismo y define cuál será su posición frente a este; además, recordando que Colombia está consagrada al Sagrado Corazón de Jesús, insiste en que el país está protegido ante las sectas y el bolchevismo de Lenin. Asimismo se expresa sobre el comunismo en México y España. Figueroa Salamanca, Helwar Fernando. "Monseñor Miguel Ángel Builes, un político intransigente y escatológico (1925-1950)", en Anuario de Historia Regional y de las Fronteras, vol. XXI, núm. 1, Bucaramanga, UIS, enero-junio 2016, pp. 244-245 y 237-259.

83 "Comunismo. Manifiesto de lucha anticomunista", Op Cit., pp. 165-168.

${ }^{84}$ Ibid.

${ }^{85}$ Ibid.
} 
capellanías, colegios, hermandades religiosas ${ }^{86}$, en la que recomendaba realizar congresos que sirvieran para renovar y acrecentar la creencia de los fieles como un acto de preparación para el segundo congreso mariano "[...] estos sendos Congresillos tendrán como objeto renovar y acrecentar el fervor de los fieles para con nuestra Madre Santísima, y para que se instruyan, al mismo tiempo, en los diversos puntos de doctrina y cultos marianos" $"$. De hecho, Juan Manuel González Arbeláez estableció que el tema central de estos era María y el $\operatorname{Hogar}^{88}$, realizando un programa específico sobre la celebración de estos congresos en las parroquias de todo el país.

Posteriormente, el mismo Juan Manuel crea un reglamento de normas para la ejecución de los congresos, el cual era un texto para que el sacerdote tuviera una guía metodológica que mostraba el proceso de cómo celebrar este. En este sentido, aclaraba que las solemnidades debían durar entre uno y tres días, en el que además de la misa, comuniones generales y otras funciones eucarísticas, se tuvieran sermones, conferencias, sesiones de estudio y asambleas, acerca de la Virgen ${ }^{89}$. Asimismo, contemplaba la necesidad de explicar a los fieles y estudiar con ellos el catecismo de la virgen María ${ }^{90}$ y de erigir un monumento o estatua de la virgen, ya sea en la entrada de la parroquia o del pueblo, "[...] colocada en un lugar hermoso y visible, sobre la carretera o el camino por donde se llegaba a la población, o sobre un montículo que dominará al caserío"91. Igualmente, monseñor Juan Manuel González solicitaba revivir el interés de los fieles de recitar individualmente o en familia en las tardes el rosario en cada parroquia ${ }^{92}$ y la celebración de una serie de actividades: conciertos, veladas literarias, procesiones, consagración de las parroquias a María, etc. También se propone que para finalizar estos congresos se llevará a cabo una peregrinación a algún santuario o imagen de la virgen o de alguna parroquia vecina ${ }^{93}$ y establecer una cofradía en nombre de la virgen del Rosario ${ }^{94}$. Para finalizar el texto señalaban que cada apóstol y verdadero católico debía trabajar en su parroquia, comité y asociación en la celebración de estos congresos. Estos actos se debían realizar por ser "la voluntad de Dios"95, según lo expuesto en distintas ocasiones en publicaciones de la revista Acción. Es decir, este texto fue utilizado para avivar en todos la devoción al icono religioso y tenerla como guardiana y protectora de los hogares ante los enemigos de la iglesia.

\footnotetext{
${ }^{86}$ Figueroa Salamanca, Helwar Hernando, Op Cit., p. 193. También en: Arias, Ricardo. El episcopado Colombiano, intransigencia y laicidad (1850-2000) (Bogotá: UNIANDES/ICANH, 2003).

87 “Normas para el Congreso Mariano”, en Revista Acción, Año IX, núm. 89, Bogotá, febrero 1942, p. 2.

${ }^{88}$ Ibid., pp. 2-3.

89 "Normas para el Congreso Mariano", Op Cit., p. 3.

${ }^{90}$ Ibid.

${ }^{91}$ La A. C.C. utilizo la cuarta edición del Catecismo de la Virgen Santísima publicado en 1918 en Barcelona en los talleres de la Librería Católica Pontificia.

92 “Comentario en honor de la Santísima Virgen”, en Revista Acción, Año IX, núm. 89, Bogotá, febrero 1942, p. 11.

93 "Normas para el Congreso Mariano", Op Cit., p. 3.

${ }^{94}$ Ibid, pp. 2-3.

${ }^{95}$ Ibid.
} 


\section{Celebración de Congresos Marianos a lo largo y ancho del territorio, 1942}

En diferentes municipios del país se llevaron a cabo a lo largo del año de 1942 los congresos pro marianos y otras actividades, es decir que la celebración no fue limitada a la capital de Colombia, por el contrario, se reprodujo en las principales ciudades del país, con ceremonias, procesiones, triduos, misas campales, conciertos, coronaciones, peregrinaciones, retiros espirituales, semanas de estudio, matrimonios, comuniones de niños y niñas, primeras comuniones, confirmaciones, entre otros ${ }^{96}$.

Estos congresos tenían como objeto la formación de un bloque humano guiados por la fe, que defendía a la iglesia y a sus símbolos de cualquier ataque, que se transmutaba en La Unidad de los católicos. Es decir, existe una relación marcada de los miembros de la A. C en adherirse a un proyecto y proselitismo político-religioso con el partido conservador, enmarcado en el populismo. De esta manera, se buscaba la apelación de los fieles a este proyecto cuando el partido conservador intentaba retornar al poder en medio del dominio político de la República Liberal. Esto se sugiere por investigaciones anteriores sobre la Acción Católica Colombiana, que maneja la hipótesis que fue implementada para contrarrestar y resistir al proyecto de laicización generado por los liberales ${ }^{97}$, el avance del protestantismo y del comunismo.

De hecho, se llevaron a cabo actividades por parte de los asociados de la A. C., y utilizaron la prensa y la radio, para influir en la entronización de la Virgen en los

96 “E1 Monumento Mariano”, en Revista Acción, Año IX, núm. 92, Bogotá, mayo 1942, p. 121.

${ }^{97}$ Durante los días 25, 26 y 27 de marzo de 1942 en el colegio de la Presentación de Bogotá en la casa Provincial se realizó un Triduo para honrar a la Inmaculada Concepción. "El Monumento Mariano", $O p$ Cit., p. 143. Entre el 19 y 26 de abril de 1942 se celebró en la diócesis de Cali el congreso mariano. "Realizaciones. Las Peregrinaciones", en Revista Acción, Año IX, núm. 93, Bogotá, junio 1942, pp. 168169. "Realizaciones. La comunión de los 15.000 hombres", en Revista Acción, Año IX, núm. 93, Bogotá, junio, 1942, pp. 172-173. Mientras tanto, en el Nororiente de Colombia entre el 28 y 31 de mayo de 1942 se celebró el congreso en la diócesis de Cúcuta, festividades que tuvo lugar en las parroquias de San José y San Antonio de Cúcuta y en los barrios El Contento, Cundinamarca, San Rafael y la Magdalena. El Pbro. Daniel Jordán fue quien organizó este congreso junto a seis misioneros redentoristas durante dos semanas. “El Congreso Mariano de Cúcuta”, en Revista Acción, Año IX, núm. 94, Bogotá, julio 1942, pp. 216-219. También: Cáceres Mateus, Sergio Armando. El Pbro Daniel Jordán Contreras, 1899-1979. El Catolicismo Intransigente y el Integrismo Católico en Santander y Norte de Santander, Colombia (Alemania: Editorial Académica Española, 2015). En julio de 1942 el obispo Miguel Ángel Builes celebró el congreso en la diócesis, siendo consagrada "Nuestra Señora de las Misericordias": "Con gran esplendor celebró su Congreso Mariano la ciudad de Santa Rosa de Osos, sede episcopal”, en Revista Acción, Año IX, núm. 94, Bogotá, julio 1942, p. 223. Asimismo, se celebró del 7 al 9 de julio de 1942 el congreso en la Diócesis de Pamplona (Pamplona, San Andrés, Bochalema, Bucaramanga, entre otros). También "Decreto de Rafael Afanador y Cadena Obispo de Nueva Pamplona. Grandioso Homenaje a la Virgen María”, en Periódico La Unidad Católica, Pamplona, 22 abril de 1942, pp. 273-274. “Otros Festejos”, en Periódico La Unidad Católica. Pamplona, 25 de septiembre, 1942, pp. 656-657. Además de toda una serie de actividades en las parroquias de la Arquidiócesis de Bogotá: "Los Párrocos de Bogotá y El Congreso Mariano”, Op Cit., pp. 129-130. "Realizaciones", en Revista Acción, Año IX, núm. 92, Bogotá, mayo 1942, p. 142. También "Habla el R. P Guardián del Santuario de La Peña”, en Revista Acción, Año IX, núm. 92, Bogotá, mayo 1942, p. 132. 
hogares colombianos. Esto a través de los Congresos Células realizados por la Hora Católica en la radiodifusora La Voz de Colombia los últimos jueves de cada mes ${ }^{98}$.

Sin embargo, el proyecto religioso a nivel nacional de realizar el congreso se ve truncado para 1942, ya que Pío XII no dio su consentimiento para la celebración de este congreso para este año. Lo cual dejará en vilo y confundido a más de un católico que estuvo y participo con devoción en las celebraciones a lo largo y ancho del territorio. Solo hasta julio de 1946 se podrá llevar a cabo en Colombia, por decreto de Pío XII, como se muestra a continuación en el siguiente apartado.

\section{Entre la confusión y la quimera. Celebración del Segundo Congreso Nacional Mariano en Colombia, 1946}

La no aceptación por parte de Pío XII para que se celebrase el segundo congreso en La catedral Primada de Colombia en 1942, dejo a más de un católico confundido y a la espera, y a la jerarquía eclesiástica mal parada frente a sus fieles, pues habían difundido este, como un acontecimiento de transcendencia para la fe y la nación. En efecto, llevaban cuatro años organizando la celebración y puesta en marcha de este congreso (1939-1942), como se observa en los apartados anteriores, con gran entusiasmo y empuje con unos objetivos claros. Para la corriente tradicionalista colombiana de corte intransigente e integrista era una oportunidad única en donde la virgen unificaba las fuerzas católicas para contrarrestar a los enemigos del Reinado de Cristo. Es necesario aclarar, que al interior de la iglesia católica colombiana había dos vertientes, una a favor de la renovación de la coronación de La Virgen del Rosario y/o los que proponían a la Inmaculada Concepción. No obstante, la decisión fue del Papa Pío XII, quien establecería que la coronación debía ser de La Virgen del Carmen, esto teniendo en cuenta la expansión como patrona en varios países y por la devoción popular al escapulario y a su simbología protectora ${ }^{99}$.

En este sentido, solo hasta el año de 1946 reciben la noticia de la celebración de esta fiesta mariana en la Capital de la República. Las fechas acordadas fueron entre el sábado 13 y el martes 16 de julio de $1946^{100}$ y tenía como fin la coronación de La virgen del Carmen, como madre y reina de Colombia.

\footnotetext{
${ }_{98}$ Cáceres Mateus, Sergio Armando. "La Acción Católica Colombiana y la resistencia al proyecto de laicización del partido liberal, 1934-1942”...

${ }^{99}$ Ibid.

100 "La virgen del Carmen ha tenido especial significación devocional en Colombia para el gremio de los conductores, que suelen llevar su imagen en los vehículos y participar muy activamente en su fiesta (16 de julio). Sus devotos generalmente llevan el escapulario del Carmen como símbolo protector y con motivos piadosos. Una de las motivaciones que inspira esta devoción popular se relaciona con una especie de promesa de quien lleve devotamente el escapulario de la virgen estará protegido contra los peligros físicos y espirituales". Es una creencia popular en la cual quien muera con el escapulario se verá libres de las penas de purgatorio. Díaz Camacho, Pedro José. "María en la religiosidad popular colombiana. Fenomenología religiosa y hermenéutica teológica", en Albertus Magnus, vol. IV, núm. 2, Bogotá, Facultad de Teología, USTA, julio-diciembre de 2013, pp. 97 y 93-129. La Virgen del Carmen en Colombia es la patrona de las conductoras, la Policía Nacional, Fuerzas Armadas de Colombia, la Fuerza Aérea y la Marina, además del cuerpo de bomberos.
} 
Días atrás de la apertura de este, fueron llegando a la ciudad la jerarquía eclesiástica y los peregrinos de las delegaciones marianas de distintos lugares del país. Contó con la visita del delegado Pontificio Monseñor José Beltrami, fue organizado por el jesuita José Andrade Valderrama y se nombró como presidenta honoraria por las damas católicas de Colombia a la Sra. Bertha Puga de Lleras ${ }^{101}$, esposa del presidente Alberto Lleras Camargo.

La apertura fue declarada abierta el día 12 de julio a las 6:00 pm, por el obispo auxiliar de Bogotá, Luis Pérez Hernández. Entre las actividades que se realizaron al día siguiente, cabe señalar que la más importante fue el desfile de Obreros y Trabajadores al monumento del Cerro de de Guadalupe, el cual se inició a las dos de la tarde y fue precedido por Julio Caicedo Téllez, obispo de Barranquilla. Para el 14 de julio se programaron ceremonias religiosas en distintos templos de la ciudad. Para el 15 de julio en las horas de la noche en un templete frente al Capitolio se llevó a cabo la celebración multitudinaria de primeras comuniones y matrimonios ${ }^{102}$.

El 16 de julio de 1946 se llevó a cabo la coronación de La virgen del Carmen en La Catedral Primada de Bogotá. En medio de la celebración recibieron un radio mensaje del Papa Pío XII con motivo de la clausura del congreso. Para terminar la celebración las palabras del papa fueron rotundas e imperativas y convocaba a todos los católicos a hacerle frente al mal, argumentando que poseían la victoria por ser Colombia baluarte de la fe en América, contar con la ayuda de la virgen del Carmen y por ser un pueblo inquebrantablemente católico:

[...] animados por la más fervorosa y filial devoción a la Madre de Dios, habéis conseguido finalmente reunir, tras cuatro años de espera, vuestro Congreso Mariano Nacional.

No os sufría el corazón más aplazamiento, porque Colombia, entre sus muchos títulos de gloria y de nobleza, -que no en balde fue un día puerta para la fe y la civilización- cuenta como uno de los primeros el ser un pueblo ardientemente mariano. [...] "¡Colombia, tierra de la Virgen; Colombia, jardín mariano! ¿No será ésta una de las causas que hacen de vuestra patria como un firme baluarte de nuestra santa fe en el continente americano, hasta el punto de que, especialmente en alguna de vuestras regiones, se respira todavía aquel aura cristiana, sana, ingenua y profunda, que por desgracia va siendo ya tan rara en el ambiente viciado de nuestro siglo?

[...]. Y ahora vosotros, reunidos en Congreso Mariano nacional para honrar y coronar a la Virgen del Carmen, estáis proclamando que la Colombia es siempre Colombia, es decir, mariana, y por consiguiente, inquebrantablemente católica. [...] Y aunque el infierno no cese en sus asaltos y la violencia, la audacia y el furor de las fuerzas del mal aumenten siempre, mientras contemos con su poderoso patrocinio jamás dudaremos de la victoria.

\footnotetext{
101 "El Segundo Congreso Nacional Mariano se inaugura esta tarde. Monseñor Beltrami Presidirá las Ceremonias que iniciaran hoy”, en Periódico El Tiempo, Bogotá, viernes 12 de julio de 1946, pp. 1 y 15.

${ }^{102}$ Ibid., p. 15.
} 
La Acción Católica en la organización y puesta en marcha del Segundo Congreso Nacional...

¡La Virgen del Carmen, Reina de Colombia! Prometedle solemnemente absoluta fidelidad a la fe de vuestros padres, a la doctrina que ellos declararon fundamento de vuestra patria., a la Religión Católica, Apostólica y Romana, «fuente profusa de las bendiciones del cielo», como la llamó vuestro Libertador, el gran Simón Bolívar, en un momento solemne de vuestra vida nacional; suplicad a la Reina celestial que os conserve lo que siempre ha sido la base de la felicidad, del bienestar y de la sana alegría de vuestro pueblo: viva fe, pureza de costumbres, santidad de vida; pedidle que siga mostrándose Madre de la humanidad porque nuestro pobre siglo tiene necesidad, hoy más que nunca, de su humildad, de su sencillez y de su pureza, si no quiere acabar de despeñarse en los abismos de la soberbia, de la doblez y de la corrupción, hacia donde a pasos agigantados se precipita $[\ldots]^{103}$.

De esta manera, este congreso termina con la coronación de la Virgen del Carmen y con las palabras del sumo pontífice Pío XII.

Aunque no se pudo llevar a cabo la celebración del congreso para las fechas propuestas en 1942, constantemente la iglesia y la jerarquía eclesiástica influyó directamente para que la A.C.C. y demás organizaciones católicas entre 1940 y 1950 implementaran una serie de acciones para contrarrestar la penetración protestante y del comunismo ${ }^{104}$. Para realizar este fin, consideraban que para combatir y detener la expansión de estos errores, era necesario organizar actividades que acrecentará en el laicado la devoción a la virgen María.

\section{A manera de cierre}

La intransigencia y el integrismo católico que abanderaba la institución eclesiástica de Colombia durante finales del siglo XIX y principios del siglo XX, generó la transformación de las representaciones y expresiones religiosas de los creyentes. Este catolicismo tradicionalista se verá plasmado especialmente en Colombia en la Hegemonía Conservadora (1886-1930) y en el mandato de la República Liberal (1930-1946). Dentro de los ejemplos más representativos de este tipo de iniciativas se encuentran: la celebración del primer y segundo congreso nacional mariano (1919 y 1946), en donde la virgen maría ocupó el puesto de madre, reina y protectora de las familias y de la nación. Estás festividades eran concurridas por cientos de miles de personas, que se abarrotaban para poder escuchar con una fe absoluta y rebosante las eucaristías, entronizaciones, peregrinaciones y las coronaciones de Las Vírgenes (De Chiquinquirá y del Carmen).

Siguiendo al historiador español, Francisco Javier Ramón Solans la organización y celebración de estas fiestas religiosas nacionales permitió que se reprodujera un modelo religioso específico ${ }^{105}$, en donde los trabajos del clero y del laico eran de suma

\footnotetext{
${ }^{103}$ Ibid.

${ }^{104}$ Pío XII. Radiomensaje de Pío XII con motivo de la clausura del Congreso Mariano Nacional de Colombia, AAS 38, Roma, 16 de julio de 1946, pp. 324-326, https://w2.vatican.va/content/pius-xii/es/ speeches/1946/documents/hf_p-xii_spe_19460716_mariano-colombia.html (30 de enero de 2016).

${ }^{105}$ Figueroa Salamanca, Helwar. "Cambio de enemigo: de liberales a comunistas. Religión y política
} 
importancia para lograr el objetivo. De esta manera, organizaciones como la A. C. C., en una primera instancia sacralizan y santifican a la virgen María, luego aducen que la identidad nacional se encuentra en peligro (por el liberalismo, la masonería, el protestantismo y el comunismo), y por último, promulgan un destino nacional único (el Reinado de Cristo y de la virgen). Es decir, esta simbología posibilita penetrar en el inconsciente colectivo de los creyentes católicos del país, lo cual permitió controlar el orden social. Para lograr esta finalidad, se realizaron toda una serie de actividades encaminadas a la celebración del segundo congreso nacional mariano entre 1939 y 1942, el cual solo pudo celebrarse por decreto de Pio XII hasta julio de 1946. No obstante, y pese a los problemas presentados entre El Vaticano y la jerarquía eclesiástica del país, se reafirmó la virgen María como un símbolo de la Nación y como baluarte de la A. C.

Este integrismo católico en Colombia intento cubrir todos los espacios de la vida cotidiana de los católicos, irrumpiendo en ellos a través de la virgen María. La mayoría de conferencias y actividades realizadas antes del congreso (1939 y 1942) recalcaban el papel de María en el hogar, en el trabajo, en los sindicatos, en los colegios católicos, en el cine, en la prensa, en los teatros, en los balnearios, etc. Asimismo se llevó a cabo la creación y entronización de la virgen a la salida y entrada de los pueblos y municipios y al interior de los hogares Colombianos, siendo un accionar de la iglesia católica para implementar el modelo de familia cristiana, es decir de la Sagrada Familia, ubicándose María como madre y protectora. De esta manera, se observa que en la mayoría de ocasiones se intentaba realizar un modelo de sociedad, que tenía como punto central un tipo de mujer, basado en la figura de la virgen María.

En ese sentido, la celebración de todas estas actividades tuvo como objeto avivar la devoción de los católicos a la figura maternal de la virgen María. Es decir, por medio de la manipulación de este arquetipo ${ }^{106} \mathrm{y}$ del inconsciente colectivo pudo penetrar en la sociedad el catolicismo, implantándose la figura maternal y protectora de la virgen María. Por ejemplo, en las distintas parroquias de diferentes regiones se llevaron a cabo la celebración de congresos pro marianos (1942), que tenían como objeto la formación de un bloque humano guiados por la fe, que defendía a la Iglesia y a sus símbolos de cualquier ataque, que se transmutaba en La Unidad de los católicos y que se materializó en las concurridas procesiones y peregrinaciones en honor a la virgen María y la creación de movimientos antiliberales, antiprotestantes y anticomunistas.

De hecho, este icono maternal fue utilizado por la A. C. C para contrarrestar el trabajo realizado por el protestantismo en algunas ciudades del país. El dispositivo para lograr este objetivo fue el señalamiento y la categorización herética impuesta desde el Concilio Tridentino, la Contrarreforma y por distintas encíclicas papales del siglo XIX y XX. Esto generó una posición intransigente e integrista que será la amalgama

en Colombia, años cuarenta", en Bidegain, Ana María (coord.), Globalización y Diversidad Religiosa (Bogotá: UNAL, 2005), pp. 373-420.

${ }^{106}$ Solans Ramón, Francisco Javier (coord.). "Un Templo para la Nación Española: La Basílica del Pilar (1854-1940)”, en Hispania Sacra, vol. LXVI, Extra I, España, ene-jun 2014, pp. 453-484. 
y alimento de un clero y laicado combativo, identificado plenamente con la causa de la Fe y dispuesto a realizar lo necesario para enmendar el error. Asimismo, existe una relación marcada de los miembros de la A. C en adherirse a un proyecto políticoreligioso con el partido conservador, enmarcado en el populismo. De esta manera, se buscaba la apelación de los fieles a este proyecto cuando el partido conservador intentaba retornar al poder en medio del dominio político de la República Liberal. Esto se sugiere por investigaciones anteriores sobre la Acción Católica Colombiana, que manejan la hipótesis que fue implementada para contrarrestar y resistir el laicismo implementado por los liberales. Del mismo modo, estas actividades que convocaban a miles de católicos fueron utilizadas como un elemento de movilización de masas, con el cual la iglesia manejaba a los movimientos obreros católicos (UTC) y hacia frente a los que eran dirigidos por el liberalismo, la izquierdista o el comunismo (CTC).

Para finalizar, entre las décadas de 1910 y 1950 estos congresos se utilizaron para realizar un lanzamiento positivo, maternal y en algunos casos combativo del icono religioso de la virgen María en sus diferentes advocaciones: La virgen del Rosario de Chiquinquirá, la virgen de Lourdes, La virgen de los Remedios, La virgen del Pilar (Guerra Civil Española y anticomunista), La virgen de Fátima (Anticomunista), La Virgen del Perpetuo Socorro, La virgen del Carmen, la Inmaculada Concepción, entre otras. Es decir, a través de estos congresos por un lado, se reafirmaron las representaciones, expresiones y prácticas religiosas de cada una de las diócesis del país; y por otro, se llevó a cabo un cambio en la percepción e imaginario de los colombianos de la virgen María, lo cual preparó el espacio para la aceptación de la mayoría de católicos en 1950 del dogma Munificentissimus Deus de Pío XII de la Asunción de María al cielo ${ }^{107}$. La materialización perfecta en Colombia fue la celebración de los cien años del dogma de la Concepción Inmaculada de María promulgada por Pío IX en la bula Innefabilis Deus ${ }^{108}$ (1854), llevándose a cabo entre el 5 y 7 de diciembre de 1954 el Tercer Congreso Nacional Mariano, que tendría como objetivo la coronación de la virgen de Fátima ${ }^{109}$ en un contexto mundial inmerso en el inicio de La Guerra Fría.

\section{Fuentes}

\section{Fuentes Primarias}

\section{Archivos}

Biblioteca Luis Ángel Arango (BLAA) Hemeroteca.

\footnotetext{
${ }^{107}$ Carl Gustav, Jung. Respuesta a Job (México: Fondo de Cultura Económica) 1964, pp. 125-126; William Elvis Plata Quezada, et al., Conventos Dominicanos que Construyeron ... Op Cit., p. 318.

${ }^{108}$ Pío XII. Constitución Apostólica. Munificentissimus Deus (1950), http://www.vatican.va/holy_father/ pius_xii/apost_constitutions/documents/hf_p-xii_apc_19501101-_munificentissimus-deus_- it.html\#fn1 (11 de febrero de 2011).

109 Pío IX. Encíclica papal Ineffabilis Deus, 8 de diciembre de 1854, http://www.papalencyclicals.net/ Pius09/p9ineff.htm (27 de marzo de 2015).
} 
Archivo Arquidiocesano de Nueva Pamplona (AANP)

\section{Prensa}

Periódico El Tiempo, Bogotá, 1946.

Periódico La Unidad Católica, Pamplona, 1942. Archivo Arquidiocesano de Nueva Pamplona. (ANNP).

Revista Acción, Bogotá, 1939-1942. Biblioteca Luis Ángel Arango (BLAA).

Revista Oficial de la Acción Católica Colombiana, Bogotá, 1934. Biblioteca Luis Ángel Arango (BLAA).

\section{Libros}

Aquino, Tomas de. Suma de Teología V. Parte III e Índices. Cuestiones 27-30. Madrid: Biblioteca de autores Cristianos, 1994.

Conferencias Episcopales de Colombia. Tomo I, 1908-1953, Bogotá: Editorial el Catolicismo, 1956.

\section{Artículos de revistas}

“1942”, en Revista Acción, (BLAA), Bogotá, noviembre 1941.

“Comentario en honor de la Santísima Virgen”, en Revista Acción, Bogotá, febrero 1942.

"Con gran esplendor celebró su Congreso Mariano la ciudad de Santa Rosa de Osos, sede episcopal”, en Revista Acción, Bogotá, julio 1942.

“Conclusiones de la Primera asamblea de Asistentes Eclesiásticos”, en Revista Acción, Bogotá, abril 1937.

"El Asistente Eclesiástico en la A. C", en Revista de la ACC, Bogotá, marzo-abril de 1934.

“El Congreso de mi pueblos”, en Revista Acción, Bogotá, junio 1942.

“El Congreso Mariano de Cúcuta”, en Revista Acción, Bogotá, julio 1942.

"El porqué de las peregrinaciones Marianas Nacionales e Interparroquiales", en Revista Acción, Año VII, núm. 72, Bogotá, agosto 1940.

“Habla el R. P Guardián del Santuario de La Peña”, en Revista Acción, (BLAA), Bogotá, mayo, 1942. 
La Acción Católica en la organización y puesta en marcha del Segundo Congreso Nacional...

"Liga de Ave María", en Revista Oficial de la Acción Católica Colombiana, Bogotá, julio 1934.

“Monumento Mariano”, en Revista Acción, Bogotá, mayo 1942.

“Normas para el Congreso Mariano” en Revista Acción, Bogotá, febrero 1942.

"Realizaciones, El Congreso Mariano de la Ciudad de Cali”, en Revista Acción, Bogotá, junio de 1942.

“Realizaciones. La comunión de diez mil niños”, en Revista Acción, Bogotá, junio de 1942

"Realizaciones. La comunión de los 15.000 hombres”, en Revista Acción, Bogotá, junio de 1942.

“Realizaciones. Las Peregrinaciones”, en Revista Acción, Bogotá, junio de 1942.

“Realizaciones”, en Revista Acción, Bogotá, mayo de 1942.

“Segundo Congreso Mariano nacional. Decreto Orgánico", en Revista Acción, Bogotá, julio de 1941.

"Semana de A.C. en el Seminario Mayor y Menor de Bogotá", en Revista Acción, Bogotá, junio de 1939.

Luis M Grignion De Montfort. "Los Apóstoles de los últimos tiempos”, en Revista Acción, Bogotá, Mayo 1939.

Reina Páez, Julio Pbro. “Congreso Mariano”, en Revista Acción, Bogotá, julio de 1942.

Ricaurte, José Eusebio. "La Virgen Poderosa es la defensora de la Iglesia", en Revista Acción, Año IX, núm. 92, Bogotá, mayo de 1942.

Rico de Herrera, Alicia. “Asociación de Señoras Católicas. Peregrinación Nacional al santuario de Nuestra Señora de Chiquinquirá”, en Revista Acción, Bogotá, agosto de 1940.

\section{Fuente Secundaria}

\section{Libros}

Arias, Ricardo. El Episcopado Colombiano. Intransigencia y laicidad (1850-2000). Bogotá: Uniandes, ICANH, CESO, 2003.

Bidegain de Uran, Ana María. Iglesia, pueblo y política. Un estudio de conflictos de intereses. Colombia, 1930-1955. Bogotá: Pontificia Universidad Javeriana, Facultad de Teología, 1985. 
Bucana, Juana B. La Iglesia Evangélica en Colombia. Una Historia. Bogotá: Buena Semilla, 1995.

Cáceres Mateus, Sergio Armando. El Pbro Daniel Jordán Contreras, 1899-1979. El Catolicismo Intransigente y el Integrismo Católico en Santander y Norte de Santander, Colombia. Alemania: Editorial Académica Española, 2015.

Castaño Rueda, Julio Ricardo. Nuestra Señora del Rosario de Chiquinquirá, historia de una tradición. Bogotá: Fundación Editorial Epígrafe, 2005.

Cornejo \& Mesanza. El minucioso relato sobre La coronación de Nuestra Señora del Rosario de Chiquinquirá. Chiquinquirá, 1919.

Dussel, D. Enrique. Historia de la Iglesia en América Latina. Bogotá: USTA, 1984.

E. Dussel, et al. Historia General de La Iglesia en América Latina T. IX Cono Sur (Argentina, Chile, Uruguay y Paraguay). España: CEHILA, Ediciones Sígueme S. A, 1994.

E. Dussel, et al. Historia General de la Iglesia en América Latina Tomo VIII (Perú, Bolivia y Ecuador). Salamanca, España: CEHILA, Ediciones Sígueme, 1987.

Flórez, Gloria Cristina. Advocaciones Mariana de Gloria. Lima: Editorial San Lorenzo del Escorial, 2012.

Jung, Carl Gustav. Respuesta a Job. México: Fondo de Cultura Económica, 1964.

Plata Quezada, William Elvis, et al. Conventos Dominicanos que Construyeron un pais. Arquitectura Dominicana, fe y sociedad en la Nueva Granada Siglos XVI-XIX. Bucaramanga: Universidad Santo Tomás, 2010.

Warner, Marina. Tú sola entre las mujeres. El mito y el culto de la Virgen María. España: Taurus Humanidades, 1991.

\section{Capítulos de Libros}

Arango de Restrepo, Gloria Mercedes y Arboleda M., Carlos. "La Constitución de Rionegro y el Syllabus como dos símbolos de nación y dos banderas de guerra", en Ortiz Mesa, Javier (ed.), Ganarse el cielo defendiendo la religión. Guerras Civiles en Colombia, 1840-1902. Bogotá: Unibiblos, 2005.

Arboleda, Carlos M. "El pluralismo religioso en Colombia", en Ortiz Mesa, Javier. (ed.), Ganarse el cielo defendiendo la religión. Guerras Civiles en Colombia, 18401902. Bogotá: Unibiblos, 2005.

Cáceres Mateus, Sergio Armando. "La Acción Católica Colombiana y la resistencia al proyecto de laicización del partido liberal, 1934-1942”, en Plata Quesada, William 
La Acción Católica en la organización y puesta en marcha del Segundo Congreso Nacional...

(ed.), El Hecho Religioso en Perspectiva Regional, Colección Escuela de Historia 25 años, Tomo II. Bucaramanga: Universidad Industrial de Santander, 2013.

Cifuentes Traslaviña, María Teresa y Florián Navas, Alicia. "El Catolicismo social: entre el Integralismo y la Teología de la Liberación”, en Bidegain, Ana María. (ed.), Historia del Cristianismo en Colombia, Corrientes y Diversidad. Bogotá: Taurus, 2005.

Figueroa Salamanca, Helwar. "Cambio de enemigo: de liberales a comunistas. Religión y política en Colombia, años cuarenta", en Bidegain, Ana María (ed.), Globalización y Diversidad Religiosa. Bogotá: UNAL, 2005.

\section{Artículos de Revista}

Abel, Christopher. "Misiones protestantes en un Estado Católico: Colombia en los años cuarenta y cincuenta”, en Revista Análisis Político, vol. L, enero-abril, 2004.

Basteros de Eleizalde, Juan Luis. "La Inmaculada Concepción en los siglos XIX y XX”, en Anuario de Historia de la Iglesia, vol. XIII, núm. 1, Salamanca, 2004.

Cortes Guerrero, José David. "Regeneración, Intransigencia y Régimen de Cristiandad”, en Revista Historia Crítica, núm. 15, 1997.

Díaz Camacho, Pedro José. "María en la religiosidad popular colombiana. Fenomenología religiosa y hermenéutica teológica" en Albertus Magnus, vol. IV, núm. 2, Bogotá, Facultad de Teología, USTA, julio-diciembre de 2012, pp. 93-129.

Figueroa Salamanca, Helwar. "Intransigencia Católica en Colombia durante los años treinta”, en Revista de Ciencias Sociales y Religión Asociación de Cientistas Sociales de la Religión de Mercosur, Año 7, 2005.

Figueroa Salamanca, Helwar Fernando. "Monseñor Miguel Ángel Builes, un político intransigente y escatológico (1925-1950)", en Anuario de Historia Regional y de las Fronteras, vol. XXI, núm. 1, enero-junio, 2016.

Londoño Botero, Rocío. "La Virgen de Chiquinquirá símbolo de identidad Nacional", en Revista de Sociología, núm 32, 2009.

López Amaya, Jeiman David. "Misiones protestantes en Colombia 1930-1946. Geografía política de la expansión evangélico pentecostal", en Anuario Colombiano de Historia Social y de la Cultura, vol. XLI, núm.2, julio-diciembre, 2017.

Pazos M., Antón. "El iter Concilio Plenario Latino Americano de 1899 o la articulación de la Iglesia latinoamericana”, en Anuario de Historia de la Iglesia, núm 7, 1998. 
Sánchez, Valentín Soria. "Historia de las fiestas de la Inmaculada Concepción en Extremadura", en La Inmaculada concepción en España: religiosidad, arte y cultura. España, Ediciones Escuerialenses, 2005.

Solans Ramón. Francisco Javier. "Un Templo para la Nación Española: La Basílica del Pilar (1854-1940)”, en Hispania Sacra, vol. LXVI, Extra I, ene-jun 2014.

Vega Rincón, Jhon Janer. "El Sínodo diocesano de Nueva Pamplona de 1872 y la disciplina sacerdotal", en Anuario de Historia Regional y de las Fronteras, vol. I, enero-junio, de 2012.

\section{Tesis}

Echavarría Uribe, Otoniel. La Herejía. Estigmatización del Protestantismo en la Diócesis de Nueva Pamplona, 1868-1943, (tesis de pregrado), UIS, 2010.

Plata Quezada, William Elvis. El catolicismo y sus corrientes en Colombia decimonónica. 1850-1880, (tesis de maestría), UNAL, 2001.

Sierra Jiménez, Esther Sofía. “El Misionero Protestante y la práctica de evangelizaciónconversión. La Misión Alianza Evangélica en el Norte de Santander 1944-1956”, (tesis de pregrado), UIS, 2008.

\section{Publicaciones en Internet}

Biografia de Luis María Grignion de Montfort, http:/www.corazones.org/santos/ luis_montfort.htm.

Coronación Canónica de la Imagen y su ocurrir histórico en el siglo XX Y XXI, http:// www.virgendechiquinquira.com/index.php?option=com_content\&view=article\&id= 44\&Itemid $=1$.

Escartín Celaya, Pedro. Apuntes para la Historia de la Acción Católica en España, http://www.accioncatolicageneral.es/index.php?option $=$ com_docman\&task $=\mathrm{doc}$ view\&gid=481.

Pío IX. Bula papal Ineffabilis Deus, 8 de diciembre de 1854, http://www. papalencyclicals.net/Pius09/p9ineff.htm.

Pío XII. Radiomensaje de Pío XII con motivo de la clausura del Congreso Mariano Nacional de Colombia. AAS 38, martes 16 de julio de 1946, https://w2.vatican.va/ content/pius-xii/es/speeches/1946/documents/hf_p-xii_spe_19460716_marianocolombia.html.

Pío XII. Constitución Apostólica. Munificentissimus Deus (1950), http://www. vatican.va/holy_padre / pius_xii / apost_constituciones / documentos / hf_p- xii apc_19501101-_munificentissimus-deus_- it.html \# na1. 